\title{
Theoretical and Experimental Research on Thermal Field Mathematical Modelling during Welding Load Operations on Active Surfaces of Milling and Cutting Teeth Used for Road Top Stripping
}

\author{
Daniela Maria IOVĂNAS \\ Transilvania University of Brasov, Romania, daniela.iovanas@unitbv.ro
}

\begin{abstract}
The ever-increasing number of vehicles on the roads has created the need to expand or rehabilitate the road infrastructure, and milling and cutting drums used for road top striping play a major role in these operations. The main components involved directly in the structure dislodging and milling process are their teeth. A tooth is basically made up of the body itself and a tungsten carbide tip that is fastened by brazing. There are currently various teeth manufacturing processes, but for our paper we chose a manufacturing process consisting of welding loading of the active part of the tooth. Under these circumstances, the brazing area may be thermally impaired. The studies described in our paper refer to the analysis performed using the finite element method of the thermal field distribution in the brazing area of the tungsten carbide tip in the cylindrical hole at the front of the tooth body, to checking the theoretical determinations made by mathematical modelling and to analysing the way in which the welding processes used thermally affect the critical target area the most.
\end{abstract}

\section{Keywords}

milling and cutting drum tooth, welding, brazing, thermal field, mathematical modelling

\section{Introduction}

The significant development of international and national road transport has currently created the need to keep existing road infrastructures functional and safe, but also to build new, modern ones. A large number of various pieces of machinery and equipment are used to build them. Depending on the work performed, a major role is played by road top stripping mills, which are used to dislodge, fragment and grind different types of road layers. Such cutters are currently made by specialized companies in a wide range of models $[1,2]$.

The main working member of the milling cutters is the milling drum, Figure 1, made up of a metal cylinder (1), on which the milling cutter teeth (2) are fastened, which represent the active component also called cutting element. They are fastened on the drum by means of a bracket (3), [1-3].

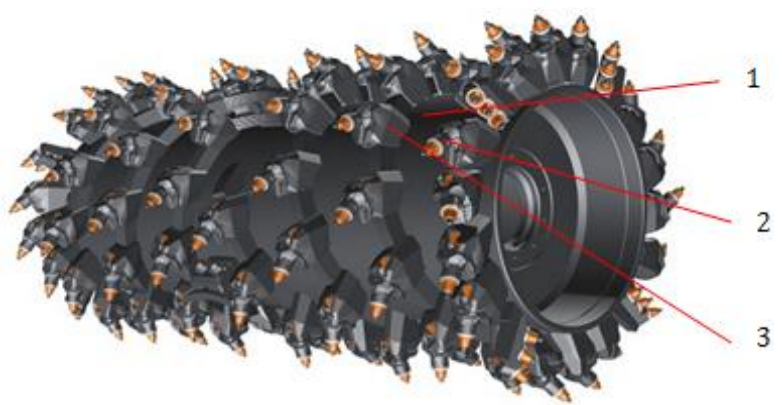

Fig. 1. Road structure cutting and milling drum 1-drum, 2- cutting tooth, 3-fastening bracket

Both the milling cutters and their teeth are manufactured in various variants, the difference between them consisting in: the shape and sizes of the active parts, the nature of the milled material, the milling technique used, the milling depth and the characteristics of the milling machines $[1,4]$. 
Figure 2 shows the components of a milling cutter tooth [5].

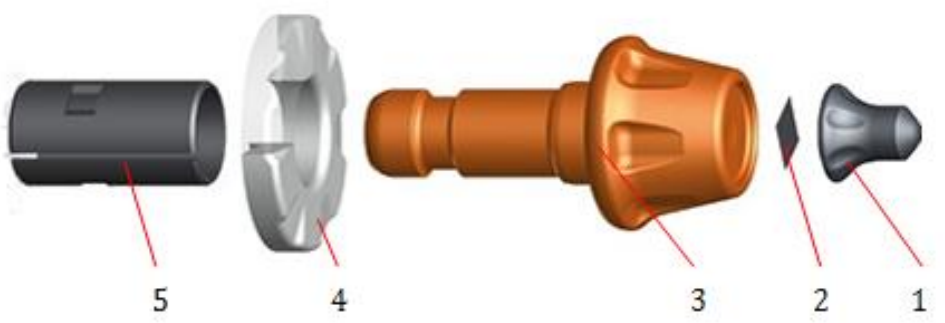

Fig. 2. Components of a milling cutter tooth

1-tungsten carbide tip, 2-brazing disc, 3- body, 4-wear plate, 5- clamping sleeve

The body of the tooth is manufactured using different technologies depending on the manufacturer, being made of 41Cr4 (EN 10083-1) steel, in which the tungsten carbide tip is fastened by brazing.

Our research focused on the use of different manufacturing technologies by welding loading in the active area of intelligent anti-wear and anti-lock protection systems on rotation, while providing greater durability and reliability [6-8].

Figure $3[1,2]$ shows a cutting tooth with the two active areas, namely the tungsten carbide tip (1) and the frustoconical section of the cutting tooth body (4), our aim being to increase its wear resistance by depositing, by welding, annular cords (2) of adequate width and thickness, with high wear resistance and self-locking protection while rotating around its own axis [7-9].

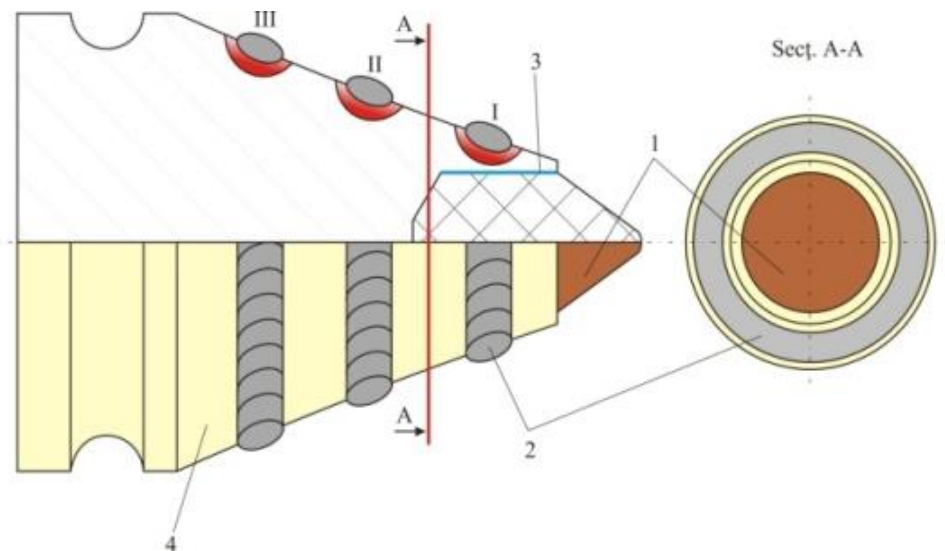

Fig. 3. Loaded cutting tooth

1- tungsten carbide tip, 2- annular cords achieved by welding loading, 3-brazing area of the tungsten carbide tip in the front hole, 4 - frustoconical section of the cutting tooth

The welding processes used in the research to load the annular cords of the active tapered section of the cutting tooth body, as well as the filler materials used in our experiments are shown in Table 1 [1].

Table 1. Filler materials and procedures used in our experiments

\begin{tabular}{|c|c|c|}
\hline No. & Welding procedure & Filler material \\
\hline 1. & MIG-MAG & FILEUR DUR 606 B \\
\hline 2. & WIG & FILEUR DUR 606 B \\
\hline 3. & WIG & VTCr2.5TiD \\
\hline 4. & Oxyacetylene flame & VTCr2.5TiD \\
\hline
\end{tabular}

\section{Experimental Research}

The study described in our paper refers to the detailed analysis of the thermal field that occurs during and after the welding loading operation of the frustoconical surface of the cutting teeth, particularly in 
the first circular cord deposited in the frustoconical area. We analysed how the fastening brazing area of the tungsten carbide tip in the cylindrical hole made in the front part of the cutting tooth is thermally affected. During its manufacture, the disc is fastened by CIF brazing, using a silver-based brazing alloy with a melting temperature ranging from 710 to $720^{\circ} \mathrm{C}$. The distance between the brazed area and the active outer surface of the cutting tooth body, in its front part, varies depending on the type of tooth and its taper, where deposits of annular welded cords with different filler materials were made (Figure 3) by means of the procedures shown in Table 1.

The deposits made (Figure 3) consisted of two (three) annular welded cords, in the frontal area (I-above the brazed disc), at the foot of maximum taper of the active area of the tooth (II) and, in some situations (depending on its type), mid-way (III) between the annular cords. Obviously, the cord that thermally affects the brazed area of the tungsten carbide tip the most is the annular cord at the front, in area I.

In order to know as accurately as possible the thermal field produced by the first cord (area I), we conducted a theoretical analysis, using finite elements; of the way it extends, for each of the welding processes used for loading.

\subsection{Thermal field analysis}

Simulating heat transfer in welded joints, in the case of a mobile heat source, requires fine discretization over a width area including the weld cord, along the entire length of the weld. Figure 4 shows the discretization network of the analysed tooth.

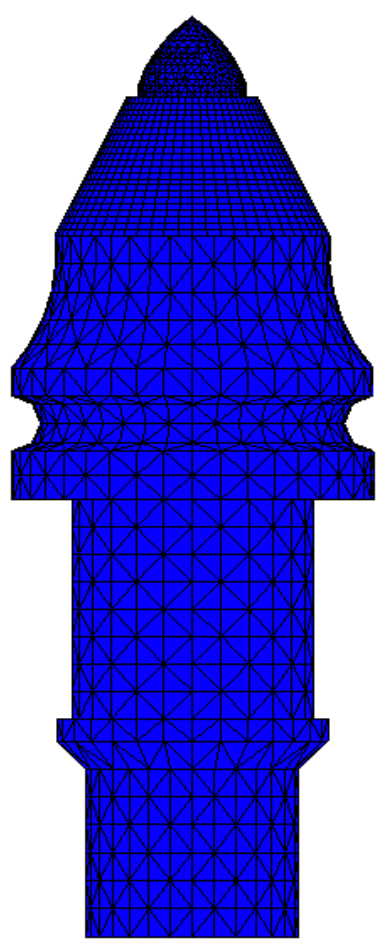

Fig. 4. Model discretization network

In the quasi-stationary phase of the welding process, the thermal field stabilizes, the extension of the thermally influenced area being the same for the moments starting with $t=4 \mathrm{~s}$.

Figures 5 and 6 show the shape of the welding bath and the isotherms of the thermal field through the part from both a side and a front view.

The cross section in Figure 6 shows temperature distribution through all three bodies: the knife body, the tungsten carbide tip and the brazing disc. It is interesting to analyse the evolution over time of the temperature in the brazing disc, taking into account the fact that its peak value must not exceed $720{ }^{\circ} \mathrm{C}$. This is also shown in Figures 7-11. 

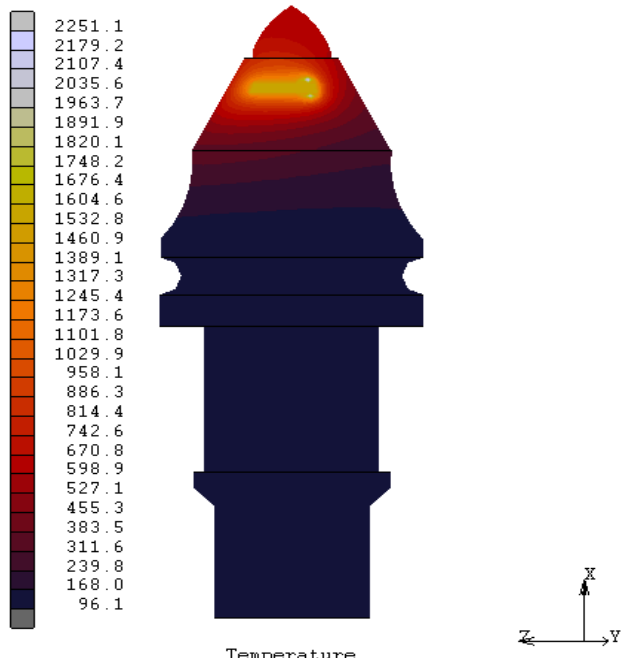

Fig. 5. Thermal field at $t=65 \mathrm{~s}-3 \mathrm{D}$ side view



Fig. 7. Thermal field in cross section

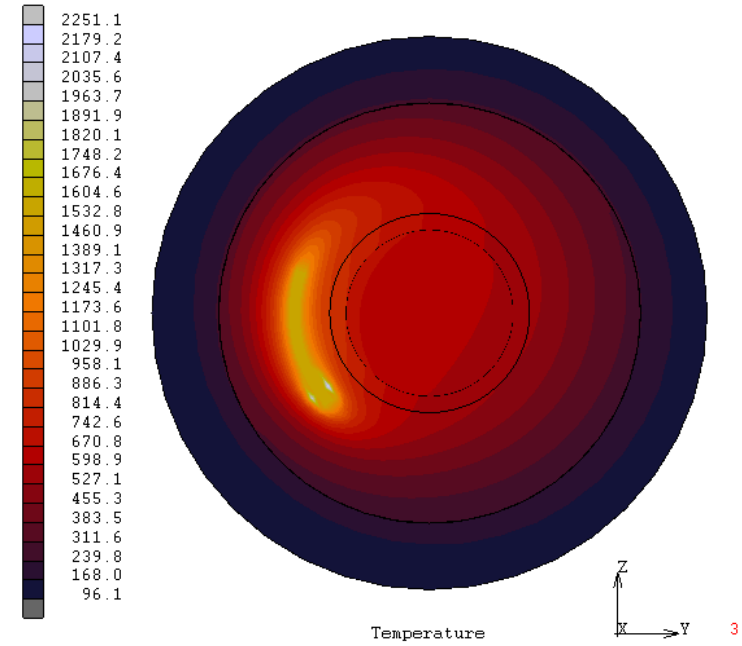

Fig. 6. Thermal field at $t=65 \mathrm{~s}-3 \mathrm{D}$ front view
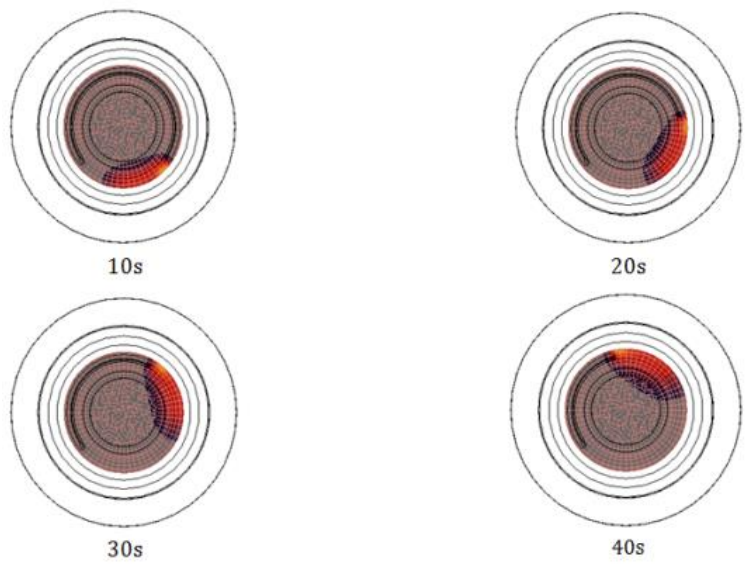

Fig. 8. Cross sections at the top of the brazing disc at different moments in time

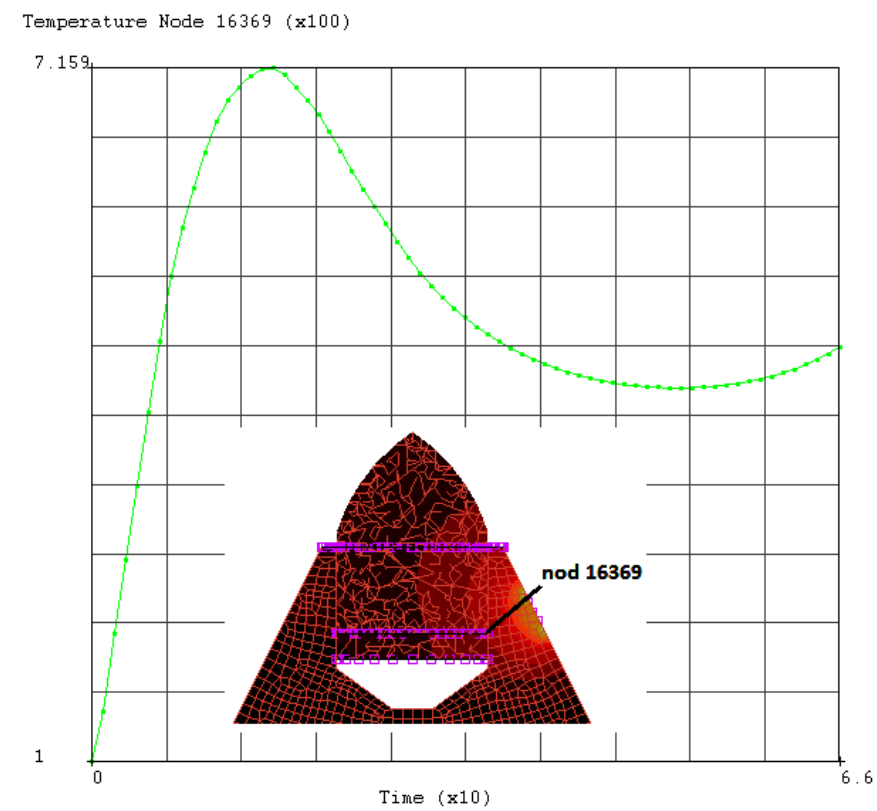

Fig. 9. Temperature variation graph in a node located at the top of the brazing disc 


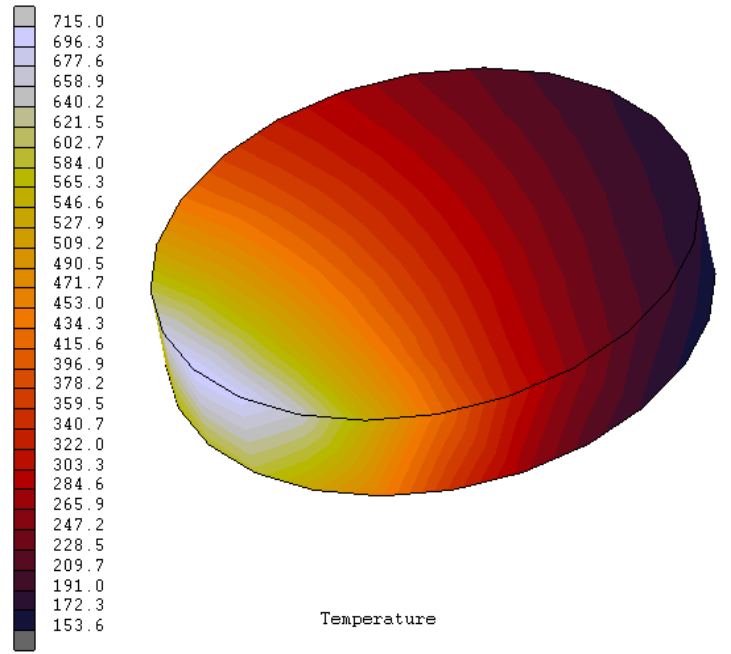

Fig. 10. Temperature distribution in the brazing disc

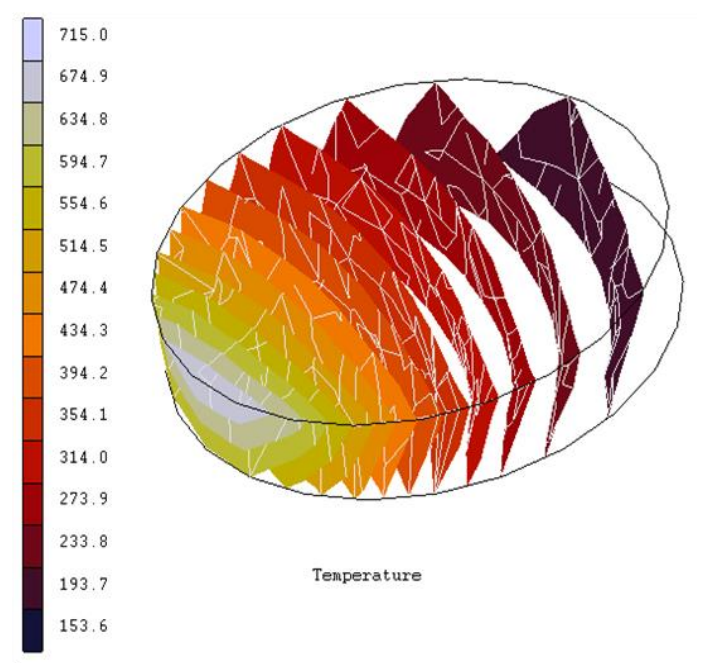

Fig. 11. Isothermal surfaces in the brazing disc

According to the information above, the suggested modelling takes into account the temperature variation of the physical-mechanical properties of the 41Cr4 (EN 10083-1) steel, which leads to obtaining very precise solutions in terms of thermal field values and distribution.

\subsection{Experimental determination of the thermal field}

The experimental assembly in Figure 12 consisted of a thermocouple placed in a calibrated 8 - 15 $\mathrm{mm}$ deep hole made in the frontal area of the tooth body in the brazing area of the tungsten carbide tip (below the area where the annular welded cord is loaded in the frontal part).

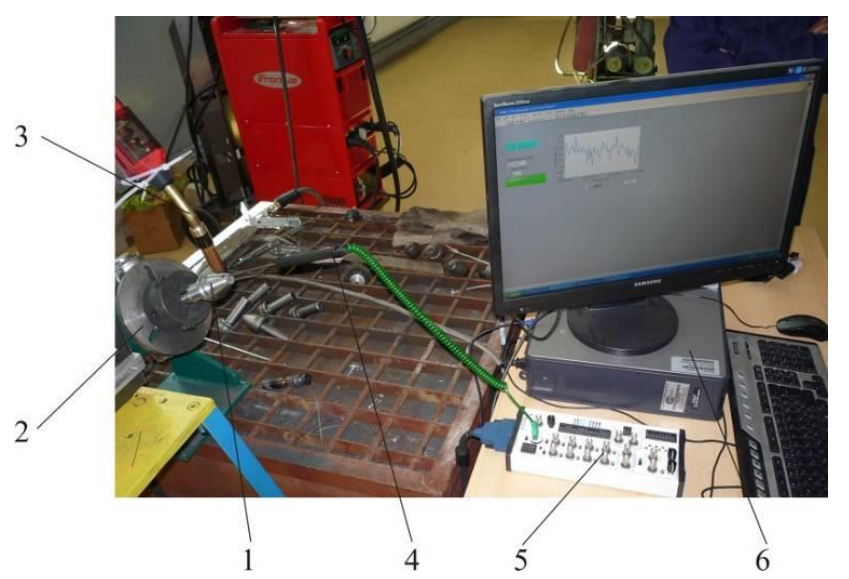

Fig. 12. Experimental assembly for measuring the temperature in the frustoconical area 1- cutting tooth, 2- rotation and positioning device, 3-welding head, 4-thermocouple, 5- data acquisition board, 6-PC

The recording of the experimental data in Figure 13 reveals the temperature variation over time when welding loading the first cord by the MAG (Figure 13, a), WIG (Figure 13, b, c), and oxyacetylene flame (Figure 13, d) processes.

\section{Results and Discussions}

The analysis of the experimental measurements of the peak temperatures reached in the brazing area, summarized in Figure 14, correlated with the hardness and metallographic determinations performed on the loads made on the active tapered area of the cutting teeth, by the welding processes used [6], reveals that the welding process that thermally affects the brazed area the most is the 
oxyacetylene flame, with a high risk of significantly weakening the brazing area of the tungsten carbide tip in the front hole. Instead, the process, correlated with the filler material used - the VTCr2.5TiD tubular rod - achieved the highest hardnesses and kept the tungsten carbide particles almost intact, enhancing the intended effect of increasing the wear and self-locking during rotation resistance of the cutting teeth.



a)



c)

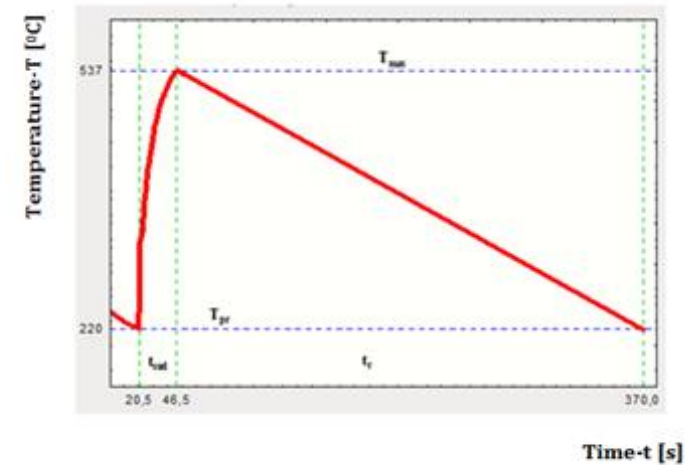

b)



d)

Fig. 13. Temperature variation over time when loading the first cord a) MAG - FILEUR DUR 606 B; b) WIG - FILEUR DUR 606 B; c) WIG - VTCr2.5TiD;

d) oxyacetylene flame - VTCr2.5TiD

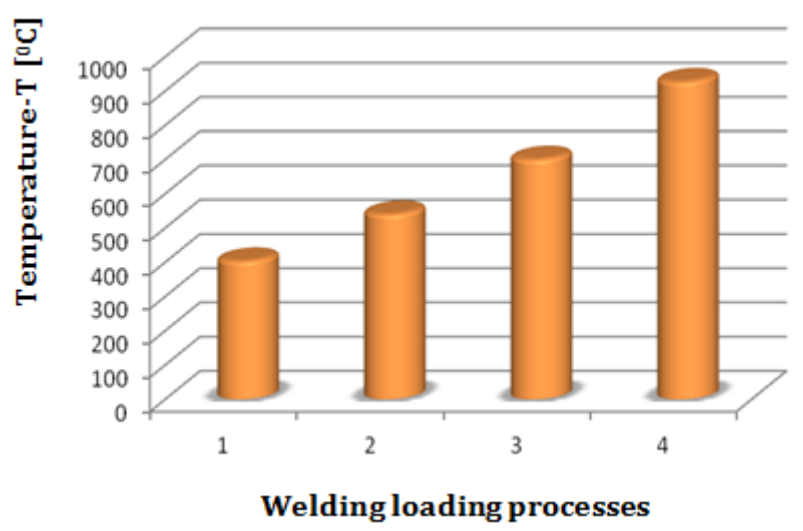

Fig. 14. Peak temperatures reached in the brazing area by the welding loading methods used (1 - MAG - FILEUR DUR 606 B; 2 - WIG - FILEUR DUR 606 B; 3 - WIG - VTCr2.5TiD; 4 - oxyacetylene flame - VTCr2.5TiD)

The WIG welding process, which uses the VTCr2.5TiD tubular rod, achieved the best results, both in terms of temperatures reached in the brazing area, below the critical one, and in terms of hardness and the intended effect of increasing wear and self-locking on rotation resistance. 
The WIG welding process, which uses FILEUR DUR 606B tubular wire, thermally affects the brazing area even less, however, due to the quality of the wire used, only an increase in wear resistance was achieved, maintaining the preferential wear danger without reducing self-locking on rotation.

The MIG/MAG welding process, which uses FILEUR DUR 606B tubular wire, achieved the lowest temperature in the critical area, however, as in the previous case, only an increase in hardness and hence wear resistance were obtained.

\section{Conclusions}

The paper discusses the analysis performed using the finite element method, the distribution of the thermal field to the experimental welding loading operations, in the brazing area of the tungsten carbide tip, in the cylindrical hole in front of the cutting tooth body.

By effectively measuring the temperatures (thermal field) in the brazing area of the tungsten carbide tip in front of the tooth body, we checked the theoretical determinations achieved by mathematical modelling and we found which of the welding processes performed thermally affect the critical target area the most.

\section{References}

1. Iovanas D.M. (2013): (Încărcarea prin sudare a pieselor uzate la utilajele terasiere). Lux Libris Publishing House, ISBN 978-973-131-209-5 (in Romanian)

2. https://www.wirtgen-group.com/en-ro/. Accessed: 2021-11-16

3. https://www.vitrac.vn/wirtgen-milling-and-cutting-drums. Accessed: 2021-11-16

4. https://www.techgong.com/. Accessed: 2021-11-16

5. https://www.monroetractor.com/milling-teeth-gen-x2/. Accessed: 2021-11-16

6. Iovanas R.F., Binchiciu E., Iovanas D.M., Trif N.I., Berchi P. (2011): Researches regarding the development of hollow rods with composite core for weld cladding. Metalurgia International, ISSN 1582-2214, Vol. 16, No. 5, pp. 133136

7. *** (2012): Performant materials and technologies designed for achieving asphalt milling tools - MATFREZ. Project type PNII, No. 188

8. Iovanas D.M., Dumitrascu A.E. (2017): Reliability estimation of the milling machines teeth obtained by welding deposition process. MATEC Web Conf., ISSN 2261-236X, Vol. 121, 8th Int. Conf. MSE 2017 "Trends in New Industrial Revolution" article 02003, https://doi.org/10.1051/matecconf/201712102003

9. Binchiciu E., Geanta V., Voiculescu I., Stefanoiu R., Iovanas R.F., Binchiciu A., Binchiciu H. (2012): Cutit de freză pentru decopertat asfalt cu protectie împotriva uzurii și autoblocării la rotire și procedeu de realizare a acestuia (Milling cutter tool for asphalt stripping, with wear-proof protection and self-blocking protection upon rotation and process for manufacturing the same). Patent RO 129863, http://online.osim.ro/pdf/ 129000-/129800-/129863.pdf (in Romanian) 